\title{
Domestic pigeons (Columba livia) discriminate between photographs of male and female pigeons
}

\author{
TAMO NAKAMURA \\ University of New South Wales, Sydney, Australia \\ MASATO ITO \\ Osaka City University, Osaka, Japan \\ and \\ DAVID B. CROFT and R. FREDERICK WESTBROOK \\ University of New South Wales, Sydney, Australia
}

\begin{abstract}
We investigated whether pigeons are able to discriminate color photographs of male and female pigeons, using a categorical discrimination procedure. In Experiments 1 and 2B, 10 out of 14 pigeons learned the discrimination. Of these, 5 pigeons showed transfer to novel stimuli, demonstrating the categorical nature of the trained discrimination. Experiment 3 showed that the discriminative behavior was based primarily on the body, as opposed to the head and the neck region. In 1 out of 3 pigeons, the discriminative behavior was maintained by the black-and-white photographs. The results suggest that some pigeons have the ability to discriminate the sex of conspecifics without behavioral cues.
\end{abstract}

Sexual indistinguishability is defined as the absence of characteristics that are sex specific, continuously displayed, and perceivable by conspecifics (Burley, 1981). Domestic pigeons (Columba livia) are considered to be sexually indistinguishable, although there are a number of features that differ between male and female pigeons. These features include the size of body, neck, and legs, the shape of nasal knobs, head, forehead, and cloaca, the degree of iridescence, vocalization, and behavior. These features vary only in degree, rather than in kind, across the sexes, forming continuous distributions with a large overlap between the two sexes, and cannot be reliably used by humans to determine the sex of pigeons (Burley, 1981; Hollander, 1942; Iwata, 1924, 1926; Levi, 1963).

It has also been suggested that pigeons are unable to distinguish the sex of conspecifics by sight (Burley, 1981; Iwata, 1924, 1926; Whitman, 1919). Burley introduced familiar or unfamiliar stimulus pigeons one at a time into large pens containing either all male or all female pigeons and observed their responses to the stimulus birds. Burley found that males courted familiar females and ignored familiar males. However, males courted unfamiliar individuals of either sex. Occasionally, females began courtship with fa-

This article is based on part of a doctoral dissertation by T.N., written while she was funded by an Australian Postgraduate Research Award. We thank Mark A. Elgar for his input into the formulation of the experiments and Peter J. Urcuioli, anonymous reviewers, and Daisuke Saeki for helpful comments on drafts of the manuscript. Part of the study was approved by the Animal Care and Ethics Committee of the University of New South Wales (ACE/CUART 88/58; ACE 92/72). Correspondence should be addressed to T. Nakamura, School of Psychology, University of Newcastle, Callaghan, NSW 2308, Australia (e-mail: tamo_nakamura@hotmail.com) or to R. F. Westbrook, School of Psychology, University of New South Wales, Sydney, NSW 2052, Australia (e-mail: f.westbrook@unsw.edu.au). miliar males, but this observation was confounded by the initiation of courtship behaviors by the stimulus male pigeons. Burley concluded that males could not assess the sex of unfamiliar individuals, because males treated all unfamiliar individuals as females. The data from females could not be interpreted, because females, for the most part, did not react differentially to familiar individuals of either sex.

The suggestion that pigeons are unable to distinguish the sex of conspecifics by sight is surprising for two reasons. First, pigeons are known for their ability to discriminate between photographs containing exemplars of such categories as humans (Herrnstein \& Loveland, 1964), pigeons (Poole \& Lander, 1971; Watanabe, 1991), birds and other animals (Roberts \& Mazmanian, 1988), cats and dogs (Ghosh, Lea, \& Noury, 2004), and individual humans and pigeons (Herrnstein, Loveland, \& Cable, 1976; Nakamura, Croft, \& Westbrook, 2003). Second, fitness benefits in terms of time and energy would accrue to an individual with the ability to discriminate between the sex of conspecifics from stationary visual cues via facilitation of choosing and courting a mate, forming pairs, breeding, and defending territories. This ability would be most useful when the conspecifics are not engaged in behaviors that could be used to determine the sex of the individuals.

A go/no-go categorical discrimination procedure with color photographs as stimuli is useful in investigating whether pigeons are able to discriminate between the different sexes of conspecifics on the basis of stationary visual cues. With this procedure, pigeons are able to discriminate between photographs of male and female frontal human faces on the basis of color, intensity gradients, and local shading (Huber, 1999; Huber, Troje, Loidolt, Aust, \& Grass, 2000; Troje, Huber, Loidolt, Aust, \& Fieder, 1999). In the go/no-go procedure, pigeons are required to peck in 
the presence of photographs belonging to an $\mathrm{S}+$ category in order to obtain reinforcement, whereas pecking in the presence of photographs belonging to an S- category is extinguished. After learning the discrimination between the two categories (e.g., male and female faces), pigeons are then tested with novel stimuli from each category to assess whether the discrimination is restricted to the training photographs. Accurate performance with novel stimuli traditionally has been considered as evidence that performances in training are not due simply to memorizing which stimuli are $\mathrm{S}+$ and which are $\mathrm{S}-$ but, instead, reflect a true categorical discrimination (e.g., Herrnstein \& Loveland, 1964; Herrnstein et al., 1976; Poole \& Lander, 1971; Roberts \& Mazmanian, 1988; Watanabe, Sakamoto, \& Wakita, 1995).

\section{EXPERIMENT 1}

In Experiment 1, we investigated whether pigeons are able to discriminate between photographs of male and female pigeons and whether this explicitly trained discrimination generalizes in testing to novel stimuli.

\section{Method}

\section{Subjects}

Five male and 3 female, experimentally naive homing pigeons (C. livia), purchased from a local breeder, were used. The age of the pigeons ranged from 1 to 10 years. The subjects were maintained at approximately $80 \%$ of their free-feeding weights throughout the experiment. The birds were housed individually in cages. The subjects were placed in the same room and, therefore, had visual, auditory, and olfactory contact with other male and female pigeons. Water and grit were available ad lib in their home cages. The colony was on a natural day-night cycle from the light coming through the windows of the colony room.

\section{Apparatus}

The apparatus was that described in a previous study (Nakamura et al., 2003, Experiment 1A). It consisted of a standard Coulbourn Instruments operant chamber. The front wall of the chamber contained a $7.0 \mathrm{~cm}(\mathrm{w}) \times 6.1 \mathrm{~cm}(\mathrm{~h})$ opaque Perspex screen. The top edge of the screen was $9.5 \mathrm{~cm}$ below the ceiling and was centered on the front wall. The pigeons had access to a grain feeder containing mixed grain through an opening centered on the front wall. The top edge of this opening was $4.1 \mathrm{~cm}$ below the bottom edge of the screen. The chamber was located in an experimental room with an air conditioning unit, which provided white noise.

Thirty-five-millimeter slides were projected onto the back of the screen by a Kodak Carousel S-AV 2050 Projector $(f=60 \mathrm{~mm})$. The lens of the projector was located about $15 \mathrm{~cm}$ from the screen, so that the projected image just filled the screen. The screen also served as the response key, and the pigeons responded directly to the screen by pecking it. A minimum force of $0.2-0.8 \mathrm{~N}$ to the screen was necessary to operate a microswitch positioned behind the bottom edge of the screen.

\section{Stimuli}

Twenty photographs, each of a different male pigeon, and 20 photographs, each of a different female pigeon, were taken from the side. The stimulus pigeons were owned by a local pigeon fancier, and the sex of the pigeons was reported to the experimenter by the owner familiar with these stimulus pigeons. We believe that the determination of the sex was accurate, since the owner was familiar with the stimulus pigeons and had access to the egg-laying history of the female pigeons. All the photographs had one pigeon in the center of the frame with a uniform green background. The photographs were taken by placing a pigeon on a perch in a photographic cage and were taken from the same camera distance $(61 \mathrm{~cm})$. Each set of 20 photographs was further divided into 10 photographs to be used in training and 10 to be used in testing. The subject pigeons were different from the stimulus pigeons and never had contact with the stimulus pigeons.

\section{Procedure}

Three male (M0984, M2928, and M4809) and 1 female (F3212) pigeons were assigned to Group Male, and 2 males (M0025 and M3546) and 2 females (F0498 and F1061) were assigned to Group Female. For Group Male, photographs of male stimulus pigeons were the positive stimuli $(\mathrm{S}+)$, and photographs of female stimulus pigeons were the negative stimuli $(\mathrm{S}-$ ). For Group Female, the opposite contingencies were in effect.

Pretraining. The procedure was similar to that described in the Discrimination Training section below, except that only the $10 \mathrm{~S}+$ were used in each round. There were three such rounds in each session, yielding a total of 30 trials, and all the trials were reinforced after a peck at an appropriate time. There were eight pretraining sessions.

Discrimination training. The training schedule was similar to that employed by Morgan, Fitch, Holman, and Lea (1976). There were $10 \mathrm{~S}+$ and $10 \mathrm{~S}-$ photographs in a session. These were presented in three rounds, giving a total of 60 trials in a session. The order of presentation was constant for each round. The photographs were randomly ordered before each training session.

In the presence of each $S+$, pecking was reinforced on a discretetrial procedure in which the duration of the trial varied from 5 to $59 \mathrm{sec}$, with a mean of $32 \mathrm{sec}$. The first response that occurred after the specified time had elapsed opened the grain feeder for $6 \mathrm{sec}$. When necessary, the presentation of an S + slide was prolonged until the subject pecked the screen after the predetermined presentation time had elapsed. Reinforcement itself was not a discriminative cue, because an $\mathrm{S}+$ trial ended as soon as reinforcement occurred. In the presence of each $\mathrm{S}-$, pecking was not reinforced, and the trial terminated at the end of the predetermined presentation time, regardless of whether the screen had been pecked or not. On all the trials, the number of pecks was recorded during the predetermined presentation time. The intertrial interval was $12.4 \mathrm{sec}$. A discrimination ratio was calculated by dividing the rate of pecking in the presence of $\mathrm{S}+$ by the sum of the rates of pecking in the presence of $\mathrm{S}+$ and $\mathrm{S}-$.

Testing. The subjects were tested some time after reaching a discrimination ratio of .73 or above. Two of the subjects were not tested, since they did not reach this criterion within 28 sessions. The discrimination ratios of the last training session for these 2 pigeons were .61 and .63 , respectively.

A test session consisted of 40 trials: 10 with photographs of male pigeons from the training sessions, 10 with new photographs of male pigeons, 10 with photographs of female pigeons from the training sessions, and 10 with new photographs of female pigeons. The photographs were presented in a random order in a single round, with an intertrial interval of $10 \mathrm{sec}$. Test sessions were carried out under extinction. All other details were the same as those described in the Discrimination Training section.

\section{Analyses}

Within-subjects differences in the peck rates in the test session were analyzed with a set of post hoc nonorthogonal contrasts, at $\alpha$ (experiment-wise $)=.05$, following a repeated measures ANOVA.

\section{Results and Discussion}

\section{Discrimination Training}

The subjects were able to discriminate between photographs of male and female pigeons. The mean and the 
standard error of the mean $(S E M)$ of the discrimination ratios on the last training session was $.77 \pm .03$ for the 6 subjects who were tested with novel stimuli. The 6 pigeons were tested after the 8th (M0984 and F1061), 12th (M4809), 16th (M2928 and F3212), and 20th (M3546) training sessions.

\section{Testing}

The discrimination ratios for the training and novel stimuli for each subject and the mean for the 6 subjects are shown in Figure 1. There were significant differences between the peck rates toward training $\mathrm{S}+$ and $\mathrm{S}-$ exemplars for all the subjects [overall, $F_{\mathrm{s}}(3,27)>6.6, p \mathrm{~s}<$ .05 ; training $\mathrm{S}+$ vs. training $\mathrm{S}-$ contrast, $F_{\mathrm{S}}(1,9)>7.0$, $p \mathrm{~s}<.05]$. This is in accordance with the results from discrimination training. There were significant differences between the peck rates toward novel $\mathrm{S}+$ and $\mathrm{S}-$ exemplars for M2928, M4809, and F3212 [novel S+ vs. novel $\mathrm{S}-$ contrast, $F \mathrm{~S}(1,9)>9.6, p \mathrm{~s}<.05]$. The mean response rates (pecks/minute) and SEMs for training $\mathrm{S}+$, novel $\mathrm{S}+$, training $\mathrm{S}-$, and novel $\mathrm{S}-$ for these 3 pigeons were $139.1 \pm 1.39,104.6 \pm 7.13,19.8 \pm 3.92$, and 26.5 \pm 6.07 , respectively. This shows that these 3 pigeons were able to discriminate between the photographs of male and female pigeons and that the discriminative behavior was not restricted to training photographs. However, there were no significant differences between the peck rates toward novel S+ and S- exemplars for M0984, M3546, and $\mathrm{F} 1061[F \mathrm{~s}(1,9)<2.7, p \mathrm{~s}>.05]$.

\section{EXPERIMENT 2A}

The main purpose of Experiment 2A was to check the training and transfer stimuli to be used in Experiment 2B.
In addition, we investigated what cues humans might use to categorize photographs of male and female pigeons.

\section{Method}

\section{Subjects}

The subjects were 2 undergraduates and 1 graduate student at the Osaka City University.

\section{Stimuli}

There were 41 photographs of male pigeons and 41 photographs of female pigeons. The photographs were digitized from the Friends of Pigeons magazine published by the Aikyu no Tomo (Friends of Pigeons) Company in Japan. The photographs were divided into male and female categories according to the sex reported in the magazine. The sex of the pigeons was reported to the magazine by the owners of the pigeons, who were familiar with their pigeons. We believe that the determination of the sex was accurate, since the owners were familiar with the stimulus pigeons and had access to the egg-laying history of the female pigeons. All the photographs had the same green background, and they were reversed around a vertical axis, if necessary, to show an image taken from the left side of the pigeon. Each picture $(9.2 \times 9.2 \mathrm{~cm})$ was printed in color on a paper with an inkjet printer. Examples of the stimuli used are shown in rows a and b of Figure 2.

\section{Procedure}

There were 82 trials in a session. The 82 pictures were randomly ordered for each subject and placed in a notebook binder. After each stimulus, a sheet of paper was inserted stating the sex of the previous picture. The subjects were tested individually, and the binder, a separate response sheet, and a questionnaire were handed to them. There were seven columns on the response sheet. In the first and second columns, the trial numbers and the picture ID numbers were printed. The subjects were required to record whether they thought the pigeon was a male or a female, the maleness rating, and the femaleness rating in columns $3-5$, respectively. After recording these, they turned the page in the binder and recorded the correct sex of the pigeon in column 6 . The subjects could write their comments in the seventh column. The experiment was conducted in Japanese, and the subjects were instructed to read the written instructions for the task

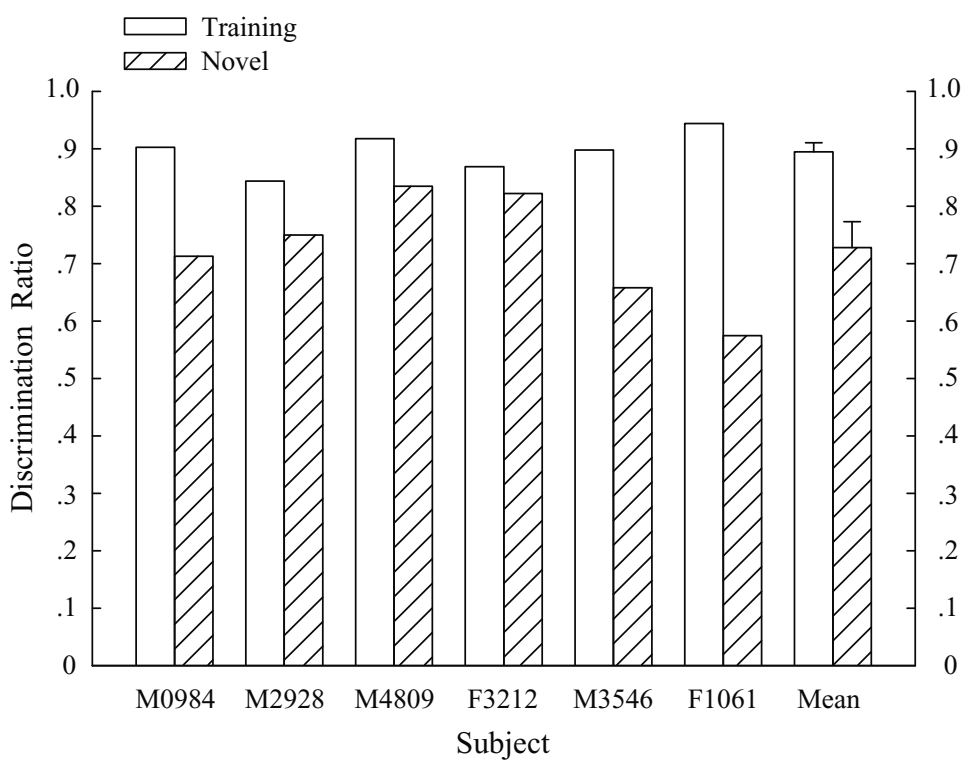

Figure 1. Individual and mean discrimination ratios for the training and novel stimuli in Experiment 1. Error bars indicate standard errors of means. 
(a) Training

(b) Novel Transfer

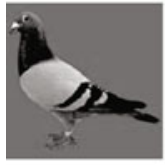

(c) Control (Chimera)
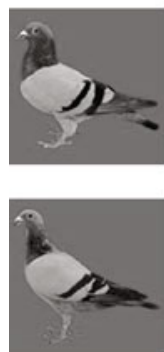

(d) Chimera

(e) Black \& White
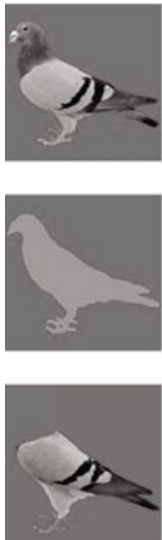

(g) Body Only

(h) Head Only
Male

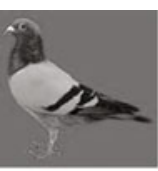

Checkered
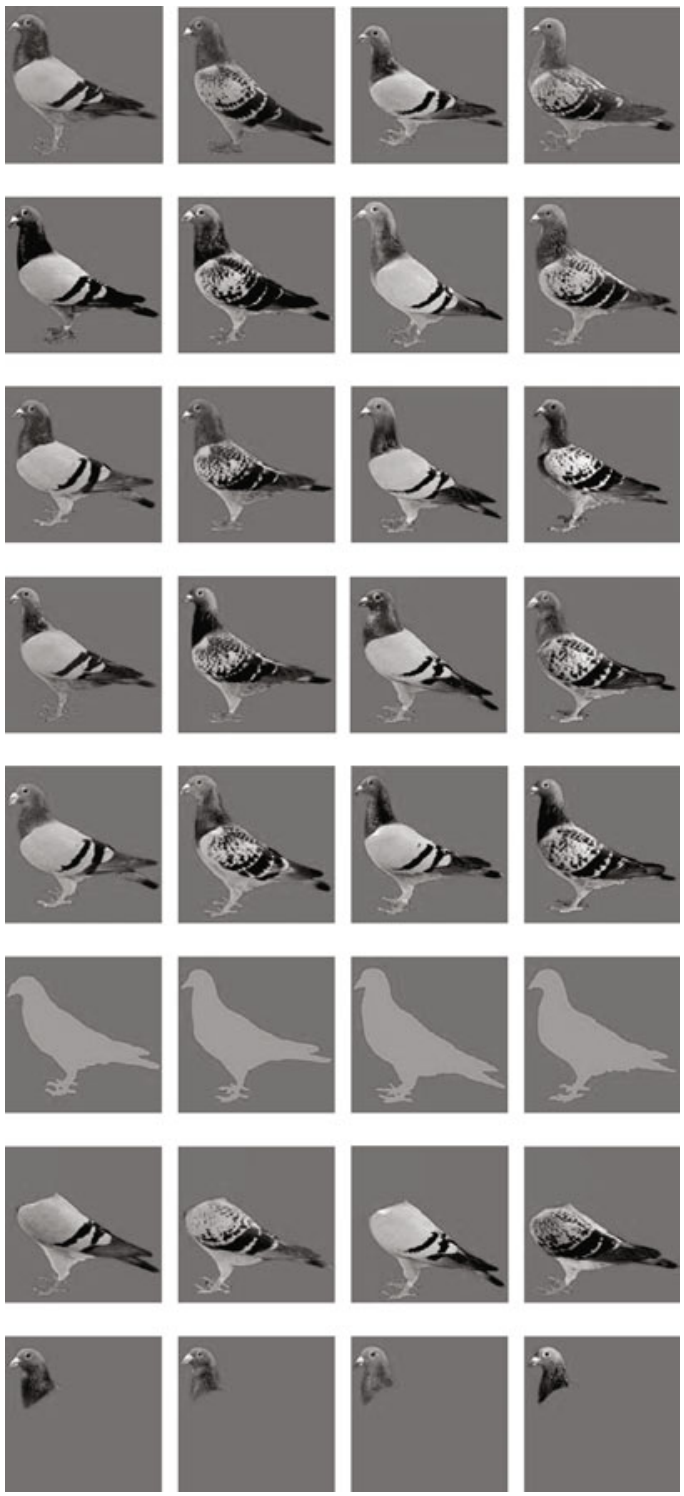

Figure 2. Examples of the stimuli used in Experiments 2A, 2B, and 3. The first two pictures in row $d$ are composed from female heads and male bodies; the last two pictures in row $d$ are composed from male heads and female bodies. and the questionnaire. After the subjects had read the instructions, the task and the questionnaire were explained orally by the experimenter. An English translation of the instructions follows:

These stimuli are for investigating whether pigeons are able to discriminate between photographs of male and female pigeons. To test whether pigeons could use other cues for the discrimination, please go through the task and complete the questionnaire. I will first explain the task. There are 82 pictures in this binder. Please look at each picture and (1) write down on the response sheet whether the pigeon is a male or a female, (2) rate the maleness of the pigeon, and (3) rate the femaleness of the pigeon. You do not need to think that there are equal numbers of male and female pigeons. Please rate the maleness and femaleness of the pigeons on a scale from 0 to 100 . For the maleness scale, 0 represents a pigeon that does not look like a male at all, and 100 represents a pigeon that looks very much like a male. For the femaleness scale, 0 represents a pigeon that does not look like a female at all, and 100 represents a pigeon that looks very much like a female. Try to use the whole range of the scales from 0 to 100 . Within the ratings for maleness and femaleness, take into consideration that there are 82 pictures and try not to give the same rating to different pictures. You may give the same rating between the maleness and the femaleness ratings. After completing this, please turn the page to where the sex of the pigeon on the previous page is stated and record the sex of the pigeon on the previous page on your response sheet. At any time, if you wish to look at the previous pictures of pigeons, feel free to do so. However, do not proceed to the next page until you record your three answers on the response sheet for the picture. If you accidentally turned the page before answering the three questions, please record on your response sheet that this happened. If you have any comments on the pictures, write down your comments. If you feel that 
you can categorize these pictures into a group of male pigeons and a group of female pigeons on the basis of other cues apart from the sex of the pigeons, record this in the column for comments. If you need more paper, write your comments on these extra papers and clearly indicate the trial number and the questions you are answering.

I will now explain the questionnaire. There are seven questions: (1) What cues can be used to categorize each picture into a group of male pigeons and a group of female pigeons apart from the sex of the pigeon? (2) How did you decide that a pigeon is a male? (3) How did you decide that a pigeon is a female? (4) What is it about a pigeon that makes it look like a male? (5) What is it about a pigeon that makes it look like a female? (6) What characterizes a pigeon that does not look like a male? And (7) What characterizes a pigeon that does not look like a female? You may answer these questions while performing your task or after completing your task. Please also write down anything else you noticed. There is no time restriction to complete the task and the questionnaire.

Questions 2 and 3 were included in case the subjects were unable to report cues that they used to categorize the photographs.

The subjects began the task after the experimenter had checked that the subjects understood the task. After the subjects had completed the task and the questionnaire, the subjects and the experimenter went over the subjects' answers to the questionnaire to make sure that the experimenter understood the subjects' answers.

\section{Results and Discussion}

The subjects took between 37 and 90 min to complete the task and the questionnaire. The mean accuracy and the $S E M$ of the subjects in recognizing the sex of the pictures of pigeons was $59.8 \% \pm 3.66 \%$. This value did not statistically differ from a chance performance of $50 \%$ [one-tailed one-sample $t$ tests, $t(2)=2.7, p=.06]$. Two sets of ratings for maleness of pigeons were obtained from the rating scores. One set was the raw ratings for maleness, and the other calculated set was obtained by subtracting the raw femaleness ratings from 100 . The combined ratings for maleness were calculated by averaging the two sets of ratings for each subject. The combined rating of maleness for the pictures of male pigeons $(58.7 \pm 4.77)$ was not statistically different from that of the pictures for female pigeons [49.3 \pm 0.35 ; paired $t$ test, $t(2)=2.0, p=.094]$.

The subjects reported using the plumage color, shape of the abdomen, and size to categorize the pictures according to their perceived sex of the pigeons. They reported that male pigeons have darker plumage, a thicker neck, a sterner face, a round chin, and a well-built body. Female pigeons have a lighter frame, a thinner and straighter neck, whiter plumage, and an angular or no chin. These characteristics, however, may have differed only in degree and not in kind across the sexes (e.g., Burley, 1981; Hollander, 1942; Iwata, 1924, 1926; Levi, 1963). Although the subjects reported the characteristics that they thought distinguished between male and female pigeons, these reported characteristics did not allow them to reliably categorize pigeons according to the sex. Since none of the subjects identified extraneous cues that correlated with the sex of the pigeons, 80 of the 82 pictures were used in Experiment 2B.

\section{EXPERIMENT 2B}

In Experiment 1, we found that 6 out of 8 pigeons could discriminate between photographs of male and female pigeons and that in 3 out of 6 pigeons, this discrimination transferred to novel stimuli. Since there had been no prior report (of which we were aware) that pigeons are able to discriminate between photographs of male and female pigeons, we repeated Experiment 1, using different subject pigeons, apparatus, and stimuli.

Lea (1984) suggested that transfer to novel stimuli is not sufficient to conclude that pigeons demonstrate conceptualization. There has to be a demonstration of cohesiveness among members belonging to the same category, so that explicitly changing behavior toward some members automatically induces the same behavioral change toward the others. One procedure for demonstrating the cohesiveness among members of a category consists of three phases. In the first phase, pigeons are trained on a categorical discrimination task - for example, between 20 photographs of male pigeons as the $\mathrm{S}+$ and 20 photographs of female pigeons as the $\mathrm{S}-$. In the second phase, the pigeons receive partial reversal training with half the photographs from each category. In the third phase, all 40 photographs are presented to the pigeons under extinction. Cohesiveness among members belonging to the male pigeon category and to the female pigeon category would be indicated if the $\mathrm{S}+$ versus $\mathrm{S}$ - reversals that were explicitly trained in the second phase immediately extended to the remaining photographs that were not shown in this reversal phase.

Previous attempts to provide such a demonstration with groups of stimuli that share common perceptual features have not been successful (Bhatt \& Wasserman, 1989; Jitsumori, 1993; Jitsumori \& Ohkubo, 1996). In these studies, the proportion of exemplars used in the partial reversal was small, ranging between $8.3 \%$ and $13.3 \%$. Presumably, the likelihood of the partial reversal's producing a reversal of the nonreversed exemplars increases via generalization as the proportion of reversed exemplars increases. In the previous studies, the absence of a change in behavior to stimuli that were not explicitly reversed may have been due to the pigeons' learning new responses only to the small proportion of specific exemplars during partial reversal training (Bhatt \& Wasserman, 1989).

The stimuli used in the studies by Jitsumori (1993, Experiment 2) and Jitsumori and Ohkubo (1996, Experiment 4) were not uniform. In the testing phase, the response generalized to the other stimuli belonging to the same types of stimuli as those used in the partial reversal training, but not to those belonging to the other types of stimuli. The responses may have generalized to the stimuli belonging to the other types if the pigeons had been trained with members from the other types of stimuli in the partial reversal training.

In Experiment 2B, we investigated whether the discrimination achieved in Experiment 1 was based on a concept, as defined by Lea (1984). There were two types of plumage for the photographs of male and female pigeons. We modified the designs used in previous investigations of this issue (Bhatt \& Wasserman, 1989; Jitsumori, 1993; Jitsumori \& Ohkubo, 1996) by increasing the number of stimuli used from each category and by using stimuli from both types of plumage in the partial reversal training. The percentage 
of the exemplars reversed in the partial reversal discrimination was 50\%. We also improved the design used in Experiment 1 by setting a more uniform criterion before testing with novel stimuli and counterbalancing the plumage patterns of the male and female pigeons in the photographs.

\section{Method}

\section{Subjects}

Three male and 3 female pigeons, different from those in Experiment 1 , were used. The age of the pigeons ranged from 3 to 5 years at the start of the experiment. The birds had participated in other experiments, but these experiments had not involved presentations of slides containing pigeons. The birds were housed individually in cages. The colony was on a 13-h day and 11-h night cycle from May through October and on a 12-h day and 12-h night cycle from November through April. Other details were the same as those in Experiment 1.

\section{Apparatus}

The subjects were trained in two standard operant chambers $(33.5 \mathrm{~cm}[\mathrm{w}] \times 33.5 \mathrm{~cm}[1] \times 36.5 \mathrm{~cm}[\mathrm{~h}])$. In each chamber, the front wall contained a $18 \mathrm{~cm}(\mathrm{w}) \times 8 \mathrm{~cm}(\mathrm{~h})$ clear acrylic window and three round (diam. $=2 \mathrm{~cm}$ ) response keys located on the window. The top edge of this window was $9 \mathrm{~cm}$ below the ceiling and was centered on the front wall. The centers of the response keys were $4 \mathrm{~cm}$ below the upper side of the acrylic window. A minimum force of $0.15 \mathrm{~N}$ was necessary for a response to be counted, and only the responses to the center key were counted. The pigeons had access to a grain feeder containing hemp seeds through an opening centered on the front wall. The top edge of this opening was $9 \mathrm{~cm}$ below the bottom edge of the window. There were two houselights (24 VDC each) on the ceiling. There was a water bottle at the back of the chamber, and the subjects had free access to water throughout the experiment. Each chamber was placed in a box to prevent the subjects from seeing or hearing each other. A fan on each box provided ventilation and white noise. Personal computers (PC-9801 ns/A, NEC, Japan) controlled the presentation of stimuli and data acquisition.

\section{Stimuli}

Eighty photographs of 20 different blue male pigeons, 20 different checkered male pigeons, 20 different blue female pigeons, and 20 different checkered female pigeons were used. The photographs were displayed on a liquid crystal display (CF-L10, Panasonic, Japan), which was placed $18 \mathrm{~cm}$ from the acrylic window of the chamber. A video card (Photopaq-98, Canopus, Japan) controlled the display. The size of the photographs was $9.2 \times 9.2 \mathrm{~cm}$. The subject pigeons had never seen the real stimulus pigeons.

\section{Procedure}

One male (M9441) and 2 female (F9226 and F9454) subjects were assigned to Group Male, and 2 male (M9426 and M9460) and 1 female (F9220) subjects were assigned to Group Female.

Discrimination training. There were $20 \mathrm{~S}+(10$ blue and 10 checkered) and $20 \mathrm{~S}-$ (10 blue and 10 checkered) photographs in a session. Four of these photographs are reproduced in row a of Figure 2. These were presented in two rounds, giving a total of 80 trials in a session. In the presence of each $\mathrm{S}+$, pecking was reinforced on a discrete-trial procedure in which the duration of the trial varied from 10 to $55 \mathrm{sec}$, with a mean of $32.5 \mathrm{sec}$. The first response that occurred after the specified time had elapsed opened the grain feeder. When necessary, the presentation of an $\mathrm{S}+$ slide was prolonged until the subject pecked the screen after this predetermined presentation time had elapsed. The duration of the hopper opening was adjusted for individual subjects, ranging from 3.5 to $6.0 \mathrm{sec}$. The houselight was on throughout the session. The subjects were trained until the discrimination ratio was .80 or better on 2 consecutive days. Other details were the same as those in Experiment 1.
Initial novel photograph testing. A test session consisted of 80 trials and was conducted under extinction. Each stimulus was presented for $30 \mathrm{sec}$, and each block of 40 trials contained 10 photographs of male pigeons from the training sessions, 10 novel photographs of male pigeons, 10 photographs of female pigeons from the training sessions, and 10 novel photographs of female pigeons. There were five blue and five checkered pigeons in each of these four categories. Four of the novel stimuli are shown in row b of Figure 2. All other details were the same as those described in the Discrimination Training section.

Partial reversal training. The pigeons were given eight sessions of discrimination training, described above, following initial novel photograph testing, since overtraining has been reported to facilitate reversal learning (Beale, 1970; Williams, 1966). The pigeons were then given partial reversal training. Twenty photographs, 5 from each category (blue male, checkered male, blue female, and checkered female) were then used in partial reversal training. Ten of the original $\mathrm{S}+$ photographs of blue and checkered pigeons now served as $\mathrm{S}-$ stimuli, and 10 of the original $\mathrm{S}-$ photographs of blue and checkered pigeons now served as $\mathrm{S}+$ stimuli. These 20 photographs were presented twice in a block of 40 trials, and there were two 40trial blocks per session. The order of stimulus presentation in each block of 40 trials was random. Other details were the same as those described in the Discrimination Training section.

Testing after partial reversal training. All 40 photographs used in discrimination training were used. Other details were the same as those described in the initial novel photograph testing section, and the entire session was conducted under extinction.

Full reversal training. The 40 photographs used in discrimination training were used, with the 20 original $\mathrm{S}+$ photographs $(10$ blue and 10 checkered) now serving as the $\mathrm{S}-$ stimuli and the 20 original S - photographs (10 blue and 10 checkered) now serving as the $\mathrm{S}+$ stimuli. Other details were the same as those described in the Discrimination Training section.

Second novel photograph testing. Twenty photographs from full reversal training ( 5 blue male, 5 checkered male, 5 blue female, and 5 checkered female) and 20 novel stimuli different from the 20 novel stimuli used in initial novel photograph testing ( 5 blue male, 5 checkered male, 5 blue female, and 5 checkered female) were used. Other details were the same as those described in Initial Novel Photograph Testing section. A test session consisted of 80 trials conducted in extinction.

\section{Analyses}

Analyses were the same as those in Experiment 1.

\section{Results \\ Discrimination Training \\ The pigeons in Group Female reached the criterion on} the 34th (F9220), 36th (M9460), and 80th (M9426) sessions. Bird F9454 in Group Male reached the criterion on the 25 th session, but the other 2 did not learn the discrimination after 80 sessions of training. The discrimination ratio for the latter pigeons averaged .53 on the 80 th session, and their transfer results will not be reported.

\section{Initial Novel Photograph Testing}

The discrimination ratios for each subject and the mean for the 4 subjects are shown separately for the training and novel exemplars in Figure 3. For all the subjects, the peck rates toward the training $\mathrm{S}+$ and $\mathrm{S}-$ were different [overall, $F_{\mathrm{S}}(3,57)>6.4, p \mathrm{~s}<.05$; training $\mathrm{S}+$ vs. training $\mathrm{S}-$ contrast, $\left.F_{\mathrm{s}}(1,19)>8.3, p \mathrm{~s}<.05\right]$. This supports our conclusion that these 4 pigeons learned the discrimina- 


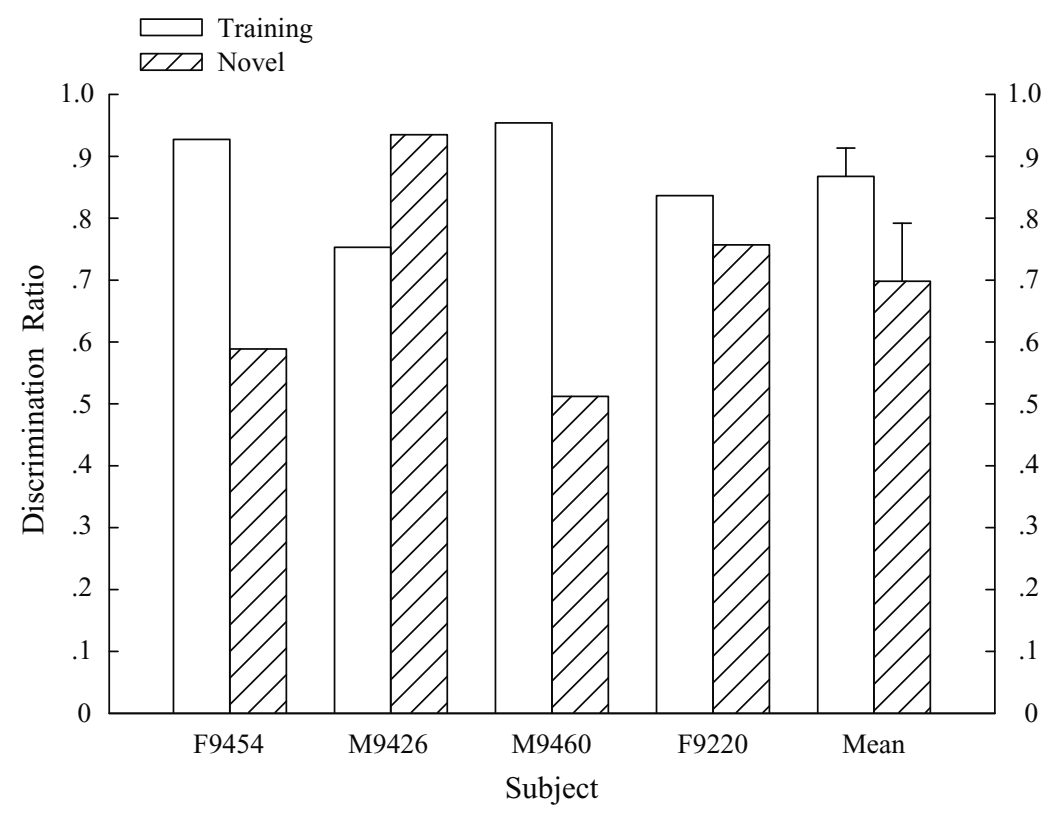

Figure 3. Individual and mean discrimination ratios for the training and novel stimuli in the initial novel photograph testing in Experiment 2B. Error bars indicate standard errors of means.

tion between the photographs of male and female pigeons used in training. The peck rates toward the novel male and female photographs were different for M9426 and F9220, indicating that this discriminative behavior partially transferred to novel stimuli for these pigeons [novel $\mathrm{S}+\mathrm{vs}$. novel $\mathrm{S}-$ contrast, $F \mathrm{~s}(1,19)>8.2, p \mathrm{~s}<.05]$. However, the peck rates toward the novel male and female photographs were not different for F9454 and M9460 [novel S+ vs. novel $\mathrm{S}-$ contrast, $F \mathrm{~s}(1,19)<1.2, p \mathrm{~s}>.05]$.

\section{Partial Reversal Training}

Three of the 4 pigeons met the criterion on the 7 th, 12 th, and 14th sessions. M9426 did not reach the criterion after 23 sessions. The discrimination ratio for this bird on the 23 rd session was .69, and this bird did not participate in testing after partial reversal training.

\section{Testing After Partial Reversal Training}

All 3 pigeons showed the same pattern of discrimination ratios toward the reversed and the nonreversed stimuli. The discrimination ratios for each subject and the mean for the 3 subjects are shown separately for the training and the novel stimuli in Figure 4. As was expected, the pigeons pecked more to the $\mathrm{S}+$ than to the $\mathrm{S}-$ stimuli used in partial reversal training [overall ANOVA, $F_{\mathrm{S}}(3,57)>$ $7.9, p \mathrm{~s}<.001$; training $\mathrm{S}+$ vs. training $\mathrm{S}-$ contrast, $\left.F_{\mathrm{S}}(1,19)>18.8, p \mathrm{~s}<.05\right]$. However, the pigeons pecked more to the original $\mathrm{S}+$ than to the original $\mathrm{S}-$ stimuli not used in partial reversal training [testing $\mathrm{S}+$ vs. testing $\mathrm{S}-$ contrast, $\left.F_{\mathrm{S}}(1,19)>6.2, p \mathrm{~s}<.05\right]$. This indicated that although the discrimination transferred to novel stimuli in initial novel photograph testing for F9220, the discrimina- tion between the photographs of male and female pigeons for this pigeon was not conceptually based, as defined by Lea (1984). All 3 pigeons behaved as though the reinforcement contingency had not been reversed for the photographs not used in partial reversal training.

\section{Full Reversal Training}

The discrimination criterion was reached on the 9th (F9220), 13th (F9454), and 16th (M9460) sessions.

\section{Second Novel Photograph Testing}

Figure 5 shows that all 3 pigeons pecked more to the $S+$ than to the $\mathrm{S}-$ stimuli in the full reversal training phase [overall ANOVA, $F \mathrm{~S}(3,57)>5.9, p \mathrm{~s}<.05$; training $\mathrm{S}+$ vs. training $\mathrm{S}-$ contrast, $F \mathrm{~S}(1,19)>10.2, p \mathrm{~s}=.05]$ but pecked equally to the novel $\mathrm{S}+$ and $\mathrm{S}-$ stimuli. Thus, the full reversal did not transfer to novel stimuli [novel S + vs. novel $\mathrm{S}-$ contrast, $\left.F_{\mathrm{S}}(1,19)<3.3, p \mathrm{~s}>.05\right]$.

\section{Discussion}

These results supported the conclusions from previous experiments that the transfer of categorical discrimination in pigeons (Jitsumori, 1993; Jitsumori \& Ohkubo, 1996) was not based on concepts, as defined by Lea (1984), despite the transfer shown by F9220 in initial novel photograph testing and the larger numbers of stimuli and the types of the stimuli used. The results indicated that such transfer was based mostly on the perceptual similarity of the training and the test stimuli (cf. Wasserman \& Astley, 1994). The present findings are consistent with the exemplar model (e.g., Medin \& Schaffer, 1978). Other models (e.g., the feature model [Jitsumori, 1993; Lea \& Ryan, 


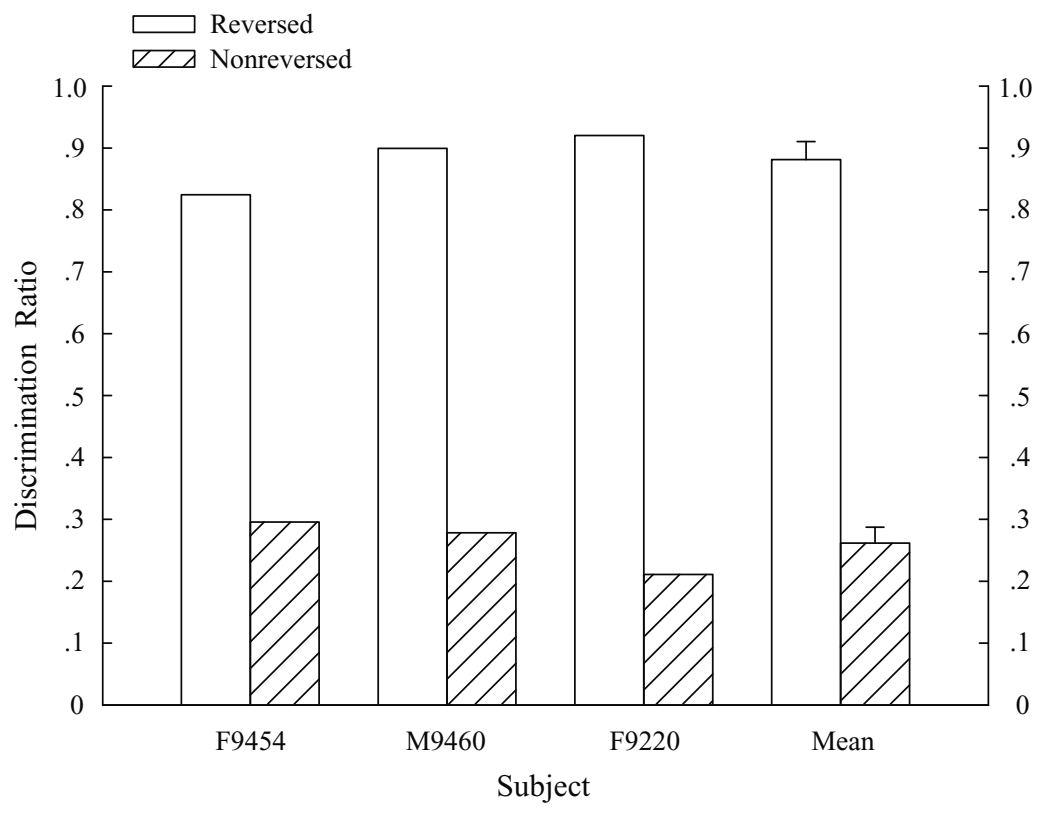

Figure 4. Individual and mean discrimination ratios for the reversed and nonreversed stimuli in testing after partial reversal training in Experiment 2B. Error bars indicate standard errors of means.

1983; von Fersen \& Lea, 1990] and the prototype model [Aydin \& Pearce, 1994; Huber \& Lenz, 1996]) of categorical discrimination predict that pigeons' behavior would generalize to the stimuli not used in the partial reversal training (cf. Shettleworth, 1998). Repeated reversals may be necessary to demonstrate the cohesiveness among stimuli belonging to a category (e.g., Vaughan, 1988).
The present results stand in contrast with those reported by Jitsumori and her colleagues (Jitsumori, 1993; Jitsumori \& Ohkubo, 1996). In their experiments, the partial reversal did transfer to stimuli not used in the reversal phase, provided that they were the same type of stimuli as those used in the partial reversal. In other words, their pigeons showed cohesiveness among stimuli of the same

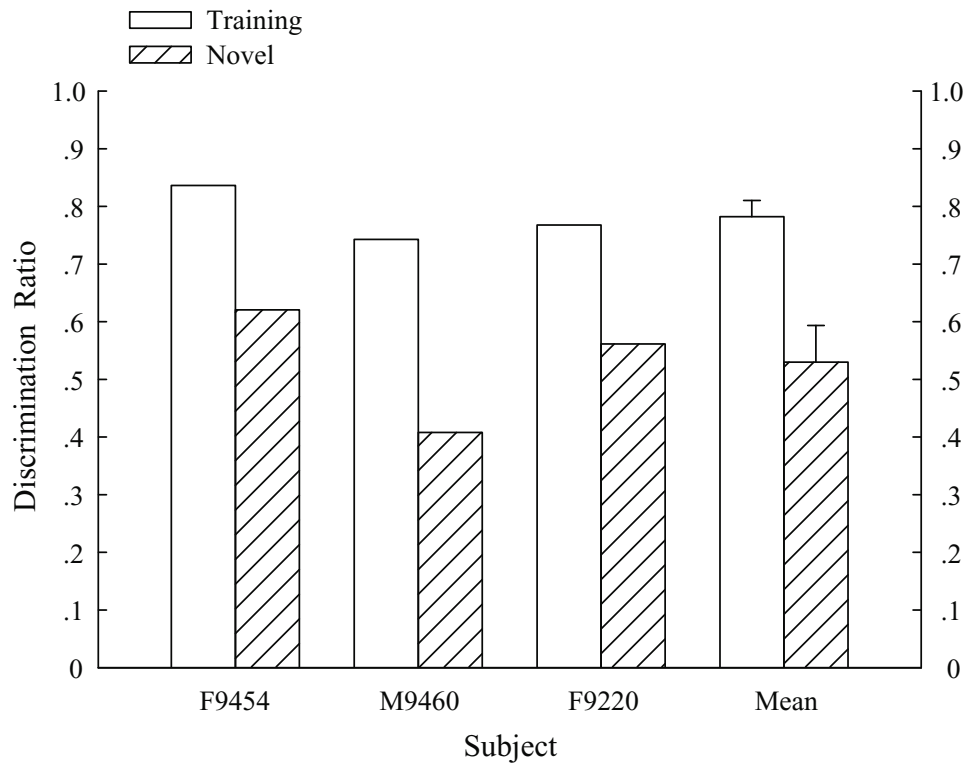

Figure 5. Individual and mean discrimination ratios for the training and novel stimuli in the second novel photograph testing in Experiment 2B. Error bars indicate standard errors of means. 
type, but not across different types of stimuli. Our pigeons did not show any cohesiveness among the stimuli belonging to the same category.

The failure of the reversal with the nonreversed exemplars, however, does not show that F9220 did not have the categories for photographs of male and female pigeons. The results from Experiment 2B and previous research merely do not provide us with evidence to conclude that pigeons use categories when solving categorical discrimination tasks. The results from these studies are still consistent with the interpretation that the pigeon may use categories in the tasks and that it also learns responses to specific exemplars during the partial reversal training.

\section{EXPERIMENT 3}

Experiment 3 investigated what types of information pigeons might use for their categorical discrimination between photographs of male and female pigeons. Ghosh et al. (2004) reported that pigeons' categorical discrimination between photographs of cats and dogs was based more on the body than on the head, although they could not distinguish between whether intermediate stimuli were considered as dogs or as $\mathrm{S}+$ exemplars, because the $\mathrm{S}+$ and $\mathrm{S}-$ stimuli were not counterbalanced across subjects. In our third experiment, we counterbalanced the reinforced category, investigated whether the pigeons' discrimination could be maintained with gray scale, shape, head, or body information, and also added a control to see whether behavior would be disrupted by chimeric stimuli. Chimeras are intermediate stimuli constructed from sections of positive and negative stimuli (e.g., Cook, Wright, \& Kendrick, 1990).

\section{Method}

\section{Subjects}

The 3 pigeons who had participated in the second novel photograph testing in Experiment $2 \mathrm{~B}$ were the subjects.

\section{Apparatus and Analysis}

The apparatus and analysis were the same as those in Experiment 2B.

\section{Stimuli and Procedure}

Testing with chimeric stimuli. The pigeons received several sessions of full reversal training before testing with chimeric stimuli. Forty photographs were used. Twelve were stimuli used in full reversal training ( 3 blue male pigeons, 3 checkered male pigeons, 3 blue female pigeons, and 3 checkered female pigeons). Fourteen were control stimuli created by making chimeras from two pigeons of the same sex and the plumage pattern. Four of these are shown in row c of Figure 2. Chimeras were formed by deleting the head and neck region of the body from one picture and the remainder of the body from the other, and aligning the two half images. There were four chimeras of blue male pigeons, three chimeras of checkered male pigeons, four chimeras of blue female pigeons, and three chimeras of checkered female pigeons. An additional 14 test stimuli were created from two pigeons of the opposite sex and the same plumage pattern, seven chimeras with a male body and a female head (four from blue pigeons and three from checkered pigeons) and seven chimeras with a female body and a male head (four from blue pigeons and three from checkered pigeons). Four of these chimeric stimuli are shown in row d of Figure 2. The first two pictures in row d are composed of female heads and male bodies, and the last two pictures are composed of male heads and female bodies. Other details were the same as those in initial novel photograph testing, and the entire session was conducted under extinction.

Testing with black-and-white photographs, photographs containing only the silhouette of the pigeon, photographs containing only the body region, and photographs containing only the head region. The 3 pigeons were tested with other types of test stimuli to determine the nature of the cues that supported discrimination of the photographs of male and female pigeons. These stimuli were tested in four different sessions. In each session, half of the stimuli were training stimuli used in full reversal training, and the other half were the remainder of the training stimuli, modified accordingly. The intact training stimuli and the modified stimuli consisted of equal numbers of the photographs of male and female pigeons. In one session, the stimulus pigeons were made black and white on the green background, four of which are shown in row e of Figure 2. In another session, the outline of the pigeon was filled with gray color, as shown in row $\mathrm{f}$ of Figure 2. The intact training stimuli not used in the black-and-white test session were used as the intact training stimuli in the silhouette test session. In another session, the head and the neck regions of the pigeon were removed, and in another session, the body region was removed for the modified photographs. Four of the body-only stimuli are shown in row g, and four of the head-only stimuli are shown in row h of Figure 2 . These test sessions were interspersed with full reversal training sessions. Other details were the same as those described in the initial novel photograph testing section.

\section{Testing With Chimeric Stimuli}

The white bars in Figure 6 show the discrimination ratios for the training stimuli for each subject and the mean for the 3 subjects. The hatched bars show the discrimination ratios for the control stimuli, which were composed of the head and the neck regions of one pigeon and the body region from another pigeon of the same sex. The gray bars show the discrimination ratios for the chimeric stimuli. The $\mathrm{S}+$ chimeric stimuli were composed of the body region of the reinforced category and the head region of the nonreinforced category. The $\mathrm{S}-$ chimeric stimuli were composed of the body region of the nonreinforced category and the head region of the reinforced category. All 3 pigeons discriminated between the photographs of male and female pigeons used in training [overall, $F_{\mathrm{s}}(5,55)>8.7, p \mathrm{~s}<.001$; training $\mathrm{S}+$ vs. training $\mathrm{S}-$ contrast, $\left.F_{\mathrm{S}}(1,11)>12.4, \mathrm{ps}<.05\right]$. Although M9460 treated chimeric stimuli with a male body as photographs of male pigeons and those with a female body as photographs of female pigeons [testing $\mathrm{S}+$ vs. testing $\mathrm{S}-$ contrast, $F(1,13)=29.5, p<.001]$, this difference was not statistically significant for F9454 or F9220 [chimeric S+ vs. chimeric $\mathrm{S}-$ contrast, $F \mathrm{~s}(1,13)<0.8, p \mathrm{~s}>.40]$. The disruption in discrimination with the chimeric stimuli, however, was not due to the joining of the head and the neck regions from one pigeon and the body region from another pigeon, because all 3 pigeons did discriminate between control stimuli that consisted of the head and the neck regions from one pigeon and the body region from another pigeon of the same sex [control S+ vs. control $\mathrm{S}-$ contrast, $\left.F_{\mathrm{S}}(1,13)>17.4, p \mathrm{~s}<.05\right]$. 


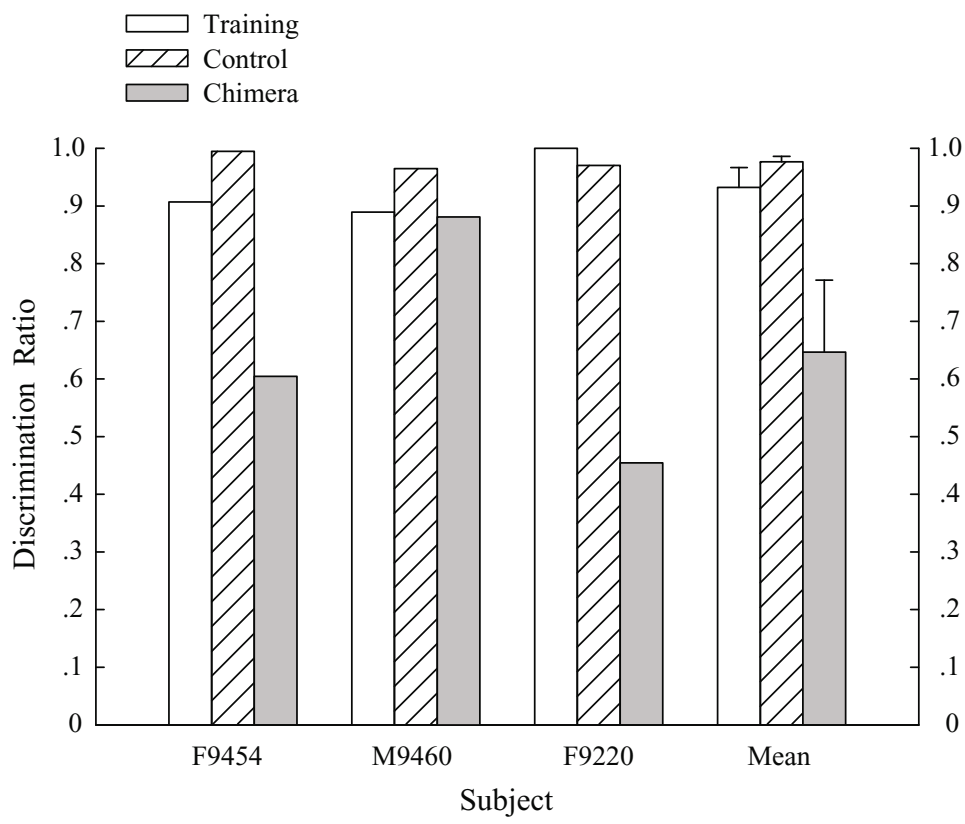

Figure 6. Individual and mean discrimination ratios for the training, control, and chimeric stimuli in the testing with chimeric stimuli in Experiment 2B. The control stimuli were composed of the body from one pigeon and the head from another pigeon of the same sex. The $S+$ chimeric stimuli were composed of the body from an $S+$ pigeon and the head from an $S-$ pigeon. The $S-$ chimeric stimuli were composed of the body from an $S-$ pigeon and the head from an $\mathrm{S}+$ pigeon. Error bars indicate standard errors of means.

Testing with black-and-white photographs, photographs containing only the silhouette of the pigeon, photographs containing only the body region, and photographs containing only the head region. The white bars in Figure 7 show the discrimination ratios for the training stimuli, and the hatched bars show the discrimination ratios for the modified testing stimuli, for each subject and the means for the 3 subjects. F9454 was able to discriminate between the photographs of male and female pigeons without the color cues [Figure 7A; overall ANOVA, $F(3,57)=19.3, p<.05$; training $\mathrm{S}+\mathrm{vs}$. training $\mathrm{S}-$ contrast, $F(1,19)=27.1, p<.001$; testing $\mathrm{S}+$ vs. testing $\mathrm{S}-$ contrast, $F(1,19)=13.4, p=.002]$. However, M9460 and F9220 were not able to discriminate between the photographs of male and female pigeons without the color cues [Figure 7A; overall ANOVA, $F_{\mathrm{s}}(3,57)>5.4, p \mathrm{~s}<.05$; training $\mathrm{S}+$ vs. training $\mathrm{S}-$ contrast, $F_{\mathrm{S}}(1,19)>11.6, p \mathrm{~s}<.05$; testing $\mathrm{S}+$ vs. testing $\mathrm{S}-$ contrast, $F \mathrm{~s}(1,19)<4.2, p \mathrm{~s}>.05]$. The performance of F9220 on the black-and-white photographs was only marginally significant $(p=.053)$. All 3 pigeons were able to discriminate between the photographs of male and female pigeons with the body region of the stimulus pigeons [Figure 7C; overall ANOVA, $F \mathrm{~s}(3,57)>7.5, p \mathrm{~s}<.001$; training $\mathrm{S}+$ vs. training $\mathrm{S}-$ contrast, $F \mathrm{~s}(1,19)>10.3$, $p \mathrm{~s}<.05$; testing $\mathrm{S}+$ vs. testing $\mathrm{S}-$ contrast, $F_{\mathrm{S}}(1,19)>$ $6.3, p \mathrm{~s}<.05]$. Since the reinforcement contingency was counterbalanced across the 3 subjects, the results from testing with the body region indicated that the subjects cat- egorized the photographs of the body region appropriately and did not treat the body region from one sex merely as positive stimuli, as was suggested by Ghosh et al. (2004).

On the other hand, none of the pigeons were able to maintain the discrimination of the photographs of the stimulus pigeons only on the basis of the silhouette [Figure 7B; overall ANOVA, $F_{\mathrm{s}}(3,57)>8.35, p \mathrm{~s}<.001$; training $\mathrm{S}+$ vs. training $\mathrm{S}-$ contrast, $F_{\mathrm{S}}(1,19)>27.12, p \mathrm{~s}<.05$; testing $\mathrm{S}+\mathrm{vs}$. testing $\mathrm{S}-$ contrast, $F_{\mathrm{S}}(1,19)<4.17, p \mathrm{~s}>.05$ ] or the head and the neck regions of the stimulus pigeons [Figure 7D; overall ANOVA, $F \mathrm{~s}(3,57)>17.9, p \mathrm{~s}<.001$; training $\mathrm{S}+$ vs. training $\mathrm{S}-$ contrast, $F \mathrm{~s}(1,19)>27.1, p \mathrm{~s}<.001$; testing $\mathrm{S}+$ vs. testing $\mathrm{S}-$ contrast, $\left.F_{\mathrm{S}}(1,19)<4.1, p \mathrm{~s}>.05\right]$. Although the discrimination ratio for the photographs of silhouette for F9220 was high, there was no significant difference in the peck rates toward the male and the female silhouettes, due to the relatively high variability in the peck rates. The discrimination ratio for the testing stimuli for F9220 with the head and the neck regions is inflated in Figure 7D because the subject did not peck in the presence of novel exemplars. The peck rates for this bird was $37.1 \pm 7.12$ (training $\mathrm{S}+$ ), $0.6 \pm 0.29$ (testing $\mathrm{S}+$ ), $0.0 \pm 0.00$ (training $\mathrm{S}-$ ), and $0.0 \pm 0.00$ (testing $\mathrm{S}-$ ). This subject did not show transfer with the head and the neck regions.

\section{GENERAL DISCUSSION}

The results from Experiments 1 and 2B showed that some pigeons have the ability to discriminate between 
A) Black and White

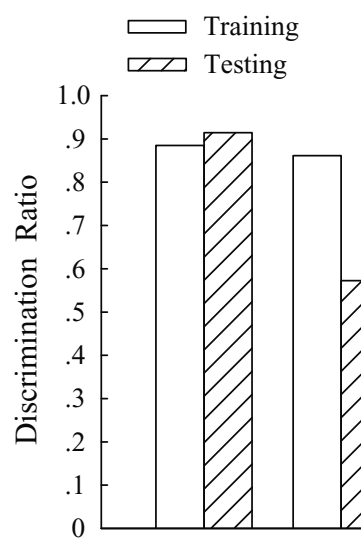

C) Body Only
B) Silhouette

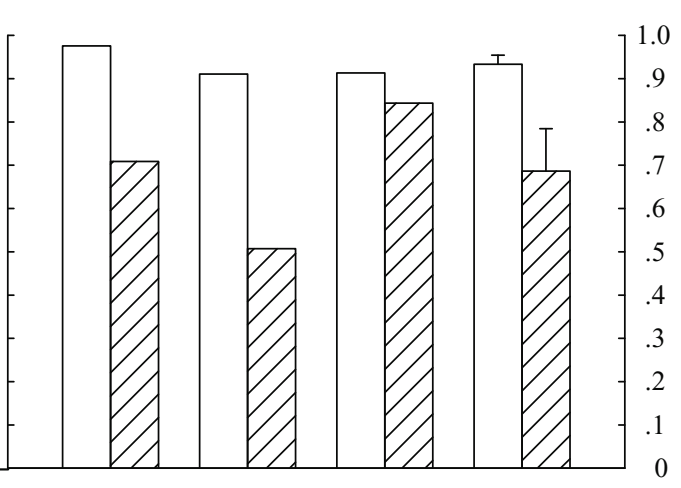

D) Head Only

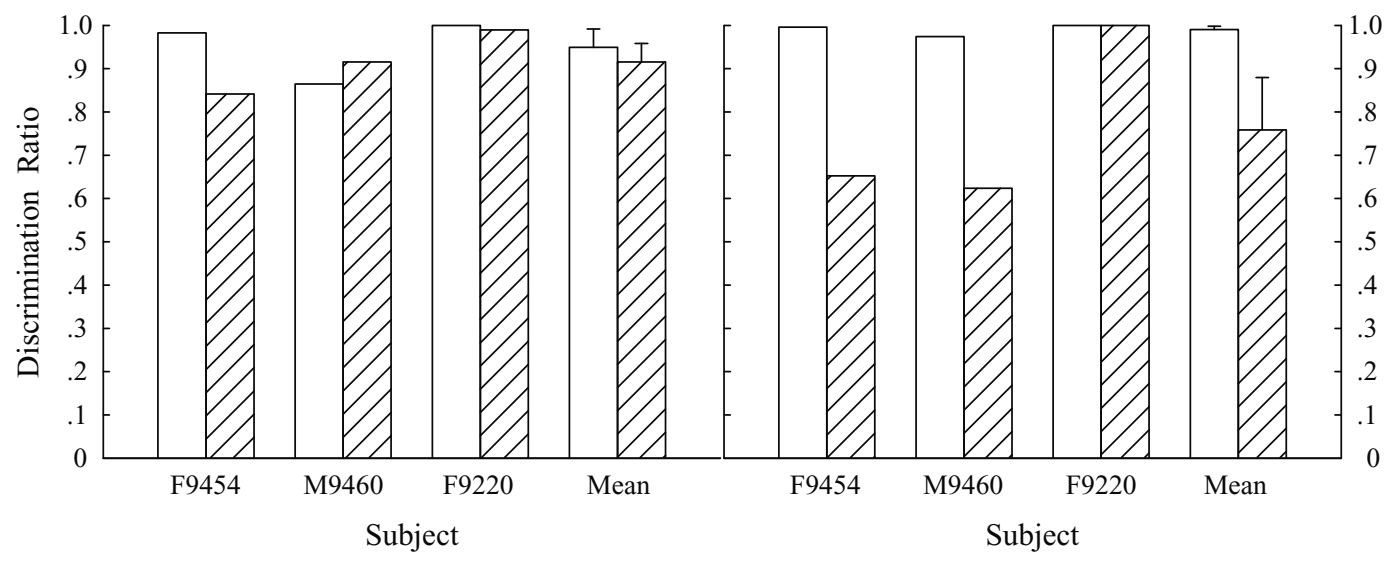

Figure 7. Individual and mean discrimination ratios for the training and testing stimuli in testing with (A) blackand-white photographs, (B) photographs containing only the silhouette of the pigeon, (C) photographs containing only the body region, and (D) photographs containing only the head region in Experiment 3. Error bars indicate standard errors of means.

photographs of male and female pigeons. Since a photograph of an object is a diminished stimulus, in comparison with the real object (Delius, Emmerton, Hörster, Jäger, \& Ostheim, 2000), and the colors depicted in the photographs do not reproduce ultraviolet light (Cuthill \& Bennett, 1993; Patterson-Kane, Nicol, Foster, \& Temple, 1997), this suggests that some pigeons are likely to have the ability to discriminate between male and female pigeons in the field without motion, auditory, olfactory, tactile, or ultraviolet cues.

Previous observational and experimental results have suggested that male pigeons do not use stationary visual cues to discriminate between male and female pigeons but rely on behavioral and interaction cues to ascertain the sex of a conspecific (Burley, 1981; Iwata, 1924, 1926; Levi, 1963; Whitman, 1919). The results from the present study suggest that this lack of sex discrimination without behavioral cues by male pigeons is not due to an inability to discriminate between male and female pigeons using stationary visual cues. In the present study, 6 out of 8 male subjects learned the discrimination, and 3 out of these 6 showed transfer to novel stimuli. Some of the behavior that male pigeons exhibit in courtship is similar to the aggressive behavior they show toward males (e.g., pursuing; Fachinelli, Torrecillas, \& Rodríguez Echandía, 2004). The discrimination measure used by Burley (1981), therefore, may not have been sensitive to the ability of male pigeons to discriminate between male and female pigeons. The use of the conditioning procedure in Experiments 1 and 2B facilitated the observation of the discriminative behavior by experimenters.

We found that some female pigeons also are able to discriminate between photographs of male and female pigeons. Four out of 6 female subjects learned the discrimination, and 2 of these 4 showed transfer to novel stimuli. This extends the findings from Burley (1981), where it was unclear whether female pigeons were able to discriminate between male and female pigeons. The results from the present experiments suggest that some females have the ability to discriminate between male and female pigeons, using stationary visual cues. Because female pigeons have been reported to be choosier in mate selection 
than are males (Burley \& Moran, 1979), some of them may actually use this ability in the field.

The results from Experiment 3 showed that the discrimination of photographs of male and female pigeons was controlled more by the body region than by the head and the neck regions. This is consistent with previous findings in which discriminations between drawings of birds and mammals and between photographs of cats and dogs by pigeons were based more on the body than on the head of the animals (Cook et al., 1990; Ghosh et al., 2004). The discrimination, however, was not based solely on the body part, since the presence of the head part from an individual of a different sex from the body part adversely affected the pigeons' discriminative behavior. All 3 pigeons were able to discriminate between the photographs of male and female pigeons' bodies. However, with chimeric stimuli, 2 out of 3 pigeons were not able to discriminate between the photographs. The behavior of Japanese quail, human infants, and adult humans, on the other hand, are controlled more by the head and/or neck regions than by the body region of the stimuli (Crawford \& Akins, 1993; Domjan \& Nash, 1988; Spencer, Quinn, Johnson, \& KarmiloffSmith, 1997).

Color information in photographs has previously been suggested to be important for the pigeons to learn the discrimination between photographs of kingfishers $(\mathrm{S}+)$ and other bird species ( $\mathrm{S}-$ ) (Roberts \& Mazmanian, 1988). In the present study, 1 out of 3 pigeons tested with modified photographs in Experiment 3 was able to discriminate between the training photographs of male and female pigeons without color information. In the studies by Huber and his colleagues, color, intensity gradients, and local shading were found to be more important than shape information in categorical discrimination of photographs of male and female human faces (Huber et al., 2000; Troje et al., 1999). Our findings from testing with silhouettes is consistent with these previous findings suggesting that the overall shape of the pigeon is not an important cue for discriminating between photographs of male and female pigeons.

\section{REFERENCES}

Aydin, A., \& Pearce, J. M. (1994). Prototype effects in categorization by pigeons. Journal of the Experimental Analysis of Behavior, 20, 264-277.

Beale, I. L. (1970). The effects of amount of training per reversal on successive reversals of a color discrimination. Journal of the Experimental Analysis of Behavior, 14, 345-352.

Bhatt, R. S., \& Wasserman, E. A. (1989). Secondary generalization and categorization in pigeons. Journal of the Experimental Analysis of Behavior, 52, 213-224.

Burley, N. (1981). The evolution of sexual indistinguishability. In R. D. Alexander \& D. W. Tinkle (Eds.), Natural selection and social behavior (pp. 121-137). New York: Chiron.

Burley, N., \& Moran, N. (1979). The significance of age and reproductive experience in the mate preferences of feral pigeons, Columba livia. Animal Behaviour, 27, 686-698.

Cook, R. G., Wright, A. A., \& Kendrick, D. F. (1990). Visual categorization by pigeons. In M. L. Commons, R. J. Herrnstein, S. M. Kosslyn, \& D. B. Mumford (Eds.), Quantitative analyses of behavior: Behavioral approaches to pattern recognition and concept formation (Vol. 8, pp. 187-214). Hillsdale, NJ: Erlbaum.
Crawford, L. L., \& AKINS, C. K. (1993). Stimulus control of copulatory behavior in male Japanese quail. Poultry Science, 72, 722-727.

Cuthill, I. C., \& Bennetr, A. T. D. (1993). Mimicry and the eye of the beholder. Proceedings of the Royal Society of London: Series B, 253, 203-204.

Delius, J. D., Emmerton, J., Hörster, W., JäGer, R., \& Ostheim, J. (2000). Picture-object recognition in pigeons. In J. Fagot (Ed.), Picture perception in animals (pp. 1-35). Hove, U.K.: Psychology Press.

Domuan, M., \& Nash, S. (1988). Stimulus control of social behaviour in male Japanese quail, Coturnix coturnix japonica. Animal Behaviour, 36, 1006-1015.

Fachinelli, C., Torrecillas, M., \& Rodríguez Echandía, E. L. (2004). Effect of naloxone on food competition aggression in foodrestricted high and low aggression pigeons (Columba livia). Brazilian Journal of Medical \& Biological Research, 37, 347-351.

Ghosh, N., LeA, S. E. G., \& Noury, M. (2004). Transfer to intermediate forms following concept discrimination by pigeons: Chimeras and morphs. Journal of the Experimental Analysis of Behavior, 82, 125-141.

Herrnstein, R. J., \& Loveland, D. H. (1964). Complex visual concept in the pigeon. Science, 146, 549-551.

Herrnstein, R. J., Loveland, D. H., \& Cable, C. (1976). Natural concepts in pigeons. Journal of Experimental Psychology: Animal Behavior Processes, 2, 285-302.

Hollander, W. F. (1942). Auto-sexing in the domestic pigeon. Journal of Heredity, 33, 135-140.

Huber, L. (1999). Generic perception: Open-ended categorization of natural classes. Cahiers de Psychologie Cognitive, 18, 845-887.

Huber, L., \& Lenz, R. (1996). Categorization of prototypical stimulus classes by pigeons. Quarterly Journal of Experimental Psychology, 49B, 111-133.

Huber, L., Troje, N. F., Loidolt, M., Aust, U., \& Grass, D. (2000). Natural categorization through multiple feature learning in pigeons. Quarterly Journal of Experimental Psychology, 53B, 341-357.

IwATA, I. (1924). Densho-bato-shiyuu-no-kantei-hoh. "Tori" the Aves, 18, 80-91.

IwATA, I. (1926). On the determination of the sexes of carrier-pigeons. Journal of the College of Agriculture, 7, 399-410.

Jitsumori, M. (1993). Category discrimination of artificial polymorphous stimuli based on feature learning. Journal of Experimental Psychology: Animal Behavior Processes, 19, 244-254.

Jitsumori, M., \& Oнкuво, O. (1996). Orientation discrimination and categorization of photographs of natural objects by pigeons. Behavioural Processes, 38, 205-226.

LEA, S. E. G. (1984). In what sense do pigeons learn concepts? In H. L. Roitblat, T. G. Bever, \& H. S. Terrace (Eds.), Animal cognition (pp. 263-276). Hillsdale, NJ: Erlbaum.

LeA, S. E. G., \& Ryan, C. M. E. (1983). Feature analysis of pigeons' acquisition of concept discrimination. In M. L. Commons, R. J. Herrnstein, \& A. R. Wagner (Eds.), Quantitative analyses of behavior: Discrimination processes (Vol. 4, pp. 239-253). Cambridge, MA: Ballinger.

LEVI, W. M. (1963). The pigeon. Sumter, SC: Levi.

Medin, D. L., \& Schaffer, M. M. (1978). Context theory of classification learning. Psychological Review, 85, 207-238.

Morgan, M. J., Fitch, M. D., Holman, J. G., \& Lea, S. E. G. (1976). Pigeons learn the concept of an "A." Perception, 5, 57-66.

Nakamura, T., Croft, D. B., \& Westbrook, R. F. (2003). Domestic pigeons (Columba livia) discriminate between photographs of individual pigeons. Learning \& Behavior, 31, 307-317.

Patterson-Kane, E., Nicol, C. J., Foster, T. M., \& Temple, W. (1997). Limited perception of video images by domestic hens. Animal Behaviour, 53, 951-963.

Poole, J., \& Lander, D. G. (1971). The pigeon's concept of pigeon. Psychonomic Science, 25, 157-158.

Roberts, W. A., \& Mazmanian, D. S. (1988). Concept learning at different levels of abstraction by pigeons, monkeys, and people. Journal of Experimental Psychology: Animal Behavior Processes, 14, 247-260.

Shettleworth, S. J. (1998). Cognition, evolution, and behavior. New York: Oxford University Press.

Spencer, J., Quinn, P. C., Johnson, M. H., \& Karmiloff-Smith, A. (1997). Heads you win, tails you lose: Evidence for young infants cat- 
egorizing mammals by head and facial attributes. Early Development \& Parenting, 6, 113-126.

Troje, N. F., Huber, L., Loidolt, M., Aust, U., \& Fieder, M. (1999). Categorical learning in pigeons: The role of texture and shape in complex static stimuli. Vision Research, 39, 353-366.

VAUGHAN, W., JR. (1988). Formation of equivalence sets in pigeons. Journal of Experimental Psychology: Animal Behavior Processes, 14, 36-42.

von Fersen, L., \& Lea, S. E. G. (1990). Category discrimination by pigeons using five polymorphous features. Journal of the Experimental Analysis of Behavior, 54, 69-84.

Wasserman, E. A., \& Astley, S. L. (1994). A behavioral analysis of concepts: Its application to pigeons and children. In D. L. Medin (Ed.), The psychology of learning and motivation: Advances in research and theory (Vol. 31, pp. 73-132). San Diego: Academic Press.
Watanabe, S. (ED.) (1991). Dohbutsu ni okeru kotaibenbetsu no kohdoh: Seirigakuteki kenkyu (Kenkyu kadai bangoh: 01450019) [Physiology of individual discrimination]. Tokyo: Keiogijyuku Daigaku.

Watanabe, S., Sakamoto, J., \& Wakita, M. (1995). Pigeons' discrimination of paintings by Monet and Picasso. Journal of the Experimental Analysis of Behavior, 63, 165-174.

Whitman, O. (1919). The behavior of pigeons: Posthumous works of Charles Otis Whitman (Vol. III). Washington: Carnegie Institution of Washington.

Williams, G. C. (1966). Adaptation and natural selection: A critique of some current evolutionary thought. Princeton, NJ: Princeton University Press.

(Manuscript received January 28, 2006; revision accepted for publication August 10, 2006.) 